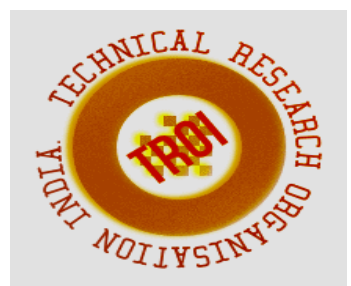

\title{
STUDY OF UTILIZATION OF FLY ASH AS A PARTIAL REPLACEMENT FOR CEMENT IN CONCRETE \\ ${ }^{1}$ Dr. Syed Ariff, ${ }^{2}$ John Gladious J, ${ }^{3}$ Ajith M, ${ }^{4}$ Uthaman A, ${ }^{5}$ Vasantharaja Sand, ${ }^{6}$ Vetrivel V Department of Mining Engineering, Dr. TTIT, KGF, Karnataka, India. \\ 11principal@drttit.edu.in, ${ }^{2}$ john@drttit.edu.in, 3ajithvasanth1998@gmail.com, ${ }^{4}$ uthaman1907@gmail.com, ${ }^{5}$ vasanthpooja30@gmail.com, ${ }^{6}$ vetriv090@gmail.com
}

\section{ABSTRACT}

Mining industry produces a large quantity of waste every year resulting in severe damage to the environment. The wastes that are produced during mining should be efficiently disposed or effectively reused for any other productive purposes. Coal and lignite mining results in considerable dust pollutions very specifically the coal beneficiation process produces extensive amount of ashes. These ashes can be utilized in construction materials rather than dumping as landfill. When dumped as landfills, these ashes have the tendency to be carried away by the wind resulting in massive damage to the surrounding environment. This study is made to investigate whether this fly ash can be used as an ingredient in concrete preparation as a partial replacement for cement by studying the strength properties of fly ash mixed concrete. The strength properties of concrete when certain percentage of cement in the concrete is replaced with fly ash are studied. The replacement percentage of cement is maintained at $10 \%, 20 \%, 30 \%, 40 \%$ and $50 \%$ and the samples are tested in the laboratory after the curing period of 21 days. The workability, tensile strength, compressive strength and shear strength of the fly ash mixed concrete sample are determined. Similar tests are conducted on concrete with no fly ash content and both results are compared to find the optimum amount of fly ash that can be replaced without compromising the quality of the concrete. By utilizing fly ash as partial replacement to cement the percentage of
CO2 emitted due to cement manufacturing can also be considerable reduced.

Keywords: Opencast, Tailing, Waste Rock, Fly Ash, Concrete, Tensile Strength, Workability Test

\subsection{Mine Wastes:}

\section{INTRODUCTION}

The wastes are generated by the mining industry which is mainly during the process of extraction, beneficiation and processing of minerals. Extraction which is the first phase that consists of initial removal of ore from the earth crust and it is done by the process of blasting which results in generation of large volume of waste. Thatis useless for the industry and is just stored in big piles within the mine lease area, and sometimes, on public land. In this way a large amount of waste is generated by the process.

The big scale of the mine, greater is the quantum of waste generated. Out of the two major types of mining methods (opencast and underground). The Opencast mining methods have more pollution intensive as they generate 8 to 10 times more quantities of waste compared to the underground mines.

1.1.1 Some major types of waste generated: 1) Waste rock:

Mine generates two types of waste rock overburden and mine development rock in Mining operations.

Surface mines that are developed results to Overburden while mine development rock is a byproduct of mineral extraction in underground mines. 
The ratio of overburden excavated to that of amount of mineral removed is called the overburden ratio or stripping ratio. For example, a stripping ratio is $4: 1$ means that 4 tons of waste rock are removed to extract one tonne of ore.

As demand for coal increases to meet the country's energy requirement, the coal companies are digging deeper and even opting for lower grades of coal. The country is even planning for production from $300 \mathrm{~m}$ depths at stripping ratio of 1:15 for $\mathrm{D}$ and $\mathrm{F}$ grade quality of coal. If these mines were operating, it would mean that even if 1 million tons of coal were extracted, it would generate 15 million tons of waste material.

\section{2) Tailings:}

This is the output of mineral beneficiation process. The minerals which cannot be used for metal extraction directly has to be concentrated before it being used. The entire process of concentration of the basic ore, is done by the grinding and milling process. Tailings are generally in the form of a slurry which contains certain hazardous contents such as arsenic, barite, calcite, cyanide, fluorite, mercury, pyrite and quartz. The slurry or the tailings is stored in a storage area called as the Tailings Dam or a Tailings Management Facility (TMF). As this tailing are very hazardous both for the human beings and too for the environment so a proper disposal method of the tailings is to be done.

All these waste materials can be disposed either by wet or dry methods but they will remain in our environment without any use to human kind. In order to make it useful to mankind then those wastes must be utilized for some purposes. One of the mine waste is fly ash it is now a days used in cement industry in the manufacturing of cement but the $100 \%$ utilization is not attained yet. In order to attain it then new ways of utilizing fly ash has to be developed. One of the way to utilize fly ash is to replace cement in the concrete mixture with fly ash this will increase the utilization percentage of fly ash and also reduce the percentage of $\mathrm{CO}_{2}$ emitted during the manufacturing of cement.

\subsection{Fly Ash:}

Generally, when coal is combusted it produces ash called coal ash. The coal ash can be divided into two categories one is bottom ash and another one is fly ash. Both the bottom ash as well as the fly ash are more hazardous but in this project we are only concerned about the fly ash and its utilization in concrete mix as a partial replacement to the cement used in the concrete.

\subsubsection{Nature of fly ash:}

Fly ash is a by-product of burning pulverized coal in an electrical generating station. Specifically, it is the unburned residue that is carried away from the burning zone in the boiler by the flue gases and then collected by either mechanical or electrostatic separators. The heavier unburned materials drop to the bottom of the furnace and is termed bottom ash; this material is not generally suitable for use as a cementitious material for concrete, but is used in the manufacture of concrete masonry block.

Fly ash is a pozzolanic material. It is a finely- divided amorphous alumino- silicate with varying amounts of calcium, which when mixed with Portland cement and water, will react with the calcium hydroxide released by the hydration of Portland cement to produce various calcium-silicate hydrates and calciumaluminate hydrates. Some fly ashes with higher amounts of calcium will also display cementitious behavior by reacting with water to produce hydrates in the absence of source of calcium hydroxide. These pozzolanic reactions are beneficial to the concrete in that they increase the quantity of the cementitious binder phase and to a lesser extent, calcium-aluminate hydrates, improving the long term strength and reducing the permeability of the system. Both of these mechanisms enhance the durability of the concrete.

\subsubsection{Composition of fly ash:}

Most commonly the fly ash contains calcium oxide $(\mathrm{CaO})$, aluminum oxide $\left(\mathrm{Al}_{2} \mathrm{O}_{3}\right)$, silicon dioxide $\left(\mathrm{SiO}_{2}\right)$ and may contain heavy metals such as arsenic, boron, cadmium, chromium, cobalt, copper, lead, mercury, molybdenum, selenium, thallium and uranium. The constituents of fly ash mainly depend on the 
constituents of the coal from which the fly ash has been generated.

\subsubsection{Classification of fly ash:}

\section{1) Class $F$}

The burning of harder, older anthracite and bituminous coal typically produces Class F fly ash. This fly ash is pozzolanic in nature, and contains less than $7 \%$ lime $(\mathrm{CaO})$. Possessing pozzolanic properties, the glassy silica and alumina of Class F fly ash requires a cementing agent, such as Portland cement, quicklime, or hydrated lime-mixed with water to react and produce cementitious compounds. Alternatively, adding a chemical activator such as sodium silicate (water glass) to a Class F ash can form a geo polymer.

\section{2) Class C}

Fly ash produced from the burning of younger lignite or sub-bituminous coal, in addition to having pozzolanic properties, also has some self-cementing properties. In the presence of water, Class C fly ash hardens and gets stronger over time. Class $\mathrm{C}$ fly ash generally contains more than $20 \%$ lime $(\mathrm{CaO})$. Unlike Class F, self-cementing Class $\mathrm{C}$ fly ash does not require an activator. Alkali and sulphate $\left(\mathrm{SO}_{4}\right)$ contents are generally higher in Class $\mathrm{C}$ fly ashes.

The lignite fly ash comes under the classification of class $\mathrm{C}$ fly ash which has lime content less than $20 \%$. The class $\mathrm{C}$ fly ash have both pozzolanic and hydraulic properties that is when it reacts with water it forms a glue like component which makes the aggregate bond together very tightly.

\subsubsection{Disposal of fly ash:}

Fly ash can be disposed in two ways,

1) Dry disposal method

2) Wet disposal method

In dry disposal method the fly ash has to be disposed in large area of land, in today's situation it is very hard to use large area of land just for the purpose of fly ash disposal.

In wet disposal also it requires large area of land or any water body to dispose the fly ash so that an impoundment can be formed.

\subsection{Utilization of fly ash in concrete:}

Historically, fly ash has been used in concrete at levels ranging from $15 \%$ to $20 \%$ by mass of the cementitious material component. The actual amount used varies widely depending on the application, the properties of the fly ash, specification limits, and the geographic location and climate higher levels (30\% to $50 \%$ ) have been used in massive structures (for example foundations and dams) to control the temperature rise in recent decades, research has reaches has demonstrated that high dosage levels ( $40 \%$ to $60 \%$ ) can be used in structural applications, producing concrete with good mechanical properties and durability.

Increasing the amount of fly ash in concrete is not without shortcomings. At high levels problems may be encountered with extended set times and slow strength development, leading to low early-age strengths and delays in the rate of construction. These drawbacks become particularly pronounced in cold-weathered concreting. Also, the durability of the concrete may be comprised with regards to resistance to deicer-salt scaling and carbonation.

For any given situation there will be an optimum amount of fly ash that can be used in concrete mixture which will maximize the technical, environmental and economic benefits of fly ash use without significantly impacting the rate of construction or impairing the longterm performance of the finished product. The optimum amount of fly ash will be a function of wide range of parameters and must be determined on a case-by-case basis.

\section{STRENGTH PROPERTY ANALYSIS OF VARIOUS CONCRETE MIXES}

\subsection{Preparation of various concrete mixtures:}

The fly as obtained from NLC India Limited, Neyveli were used for the partial replacement of the cement. The fly ash thus obtained was of class $\mathrm{C}$ category.

The ratio of cement and sand was maintained at 2:3 (Cement: Sand). 
Table 1: Ratio of materials used in concrete mixtures

\begin{tabular}{|c|c|c|c|c|}
\hline $\begin{array}{c}\text { S. } \\
\text { No } \\
\cdot\end{array}$ & $\begin{array}{c}\text { Percenta } \\
\text { ge of } \\
\text { Fly Ash }\end{array}$ & $\begin{array}{c}\text { Weight of } \\
\text { Cement(k } \\
\text { g) }\end{array}$ & $\begin{array}{c}\text { Weigh } \\
\text { t of } \\
\text { Fly } \\
\text { Ash(k } \\
\text { g) }\end{array}$ & $\begin{array}{c}\text { Weight } \\
\text { of } \\
\text { Sand(k } \\
\text { g) }\end{array}$ \\
\hline 1 & $0 \%$ (F0) & 6 & 0 & 9 \\
\hline 2 & $\begin{array}{c}10 \% \\
\text { (F10) }\end{array}$ & 5.4 & 0.6 & 9 \\
\hline 3 & $\begin{array}{c}20 \% \\
\text { (F20) }\end{array}$ & 4.8 & 1.2 & 9 \\
\hline 4 & $\begin{array}{c}30 \% \\
\text { (F30) }\end{array}$ & 4.2 & 1.8 & 9 \\
\hline 5 & $\begin{array}{c}40 \% \\
\text { (F40) }\end{array}$ & 3.6 & 2.4 & 9 \\
\hline 6 & $\begin{array}{c}50 \% \\
\text { (F50) }\end{array}$ & 3 & 3 & 9 \\
\hline
\end{tabular}

Materials used:

1) Portland Pozzolanic Cement

2) Lignite Fly Ash

3) Manufactured Sand

\subsection{Workability Test: (Slump test):}

\subsubsection{Definition:}

1) Slump is a measurement of concrete's workability, or fluidity.

2) It's an indirect measurement of concrete consistency or stiffness.

A slump test is a method used to determine the consistency of concrete. The consistency, or stiffness, indicates how much water has been used in the mix. The stiffness of the concrete mix should be matched to the requirements for the finished product quality.

\subsubsection{Concrete Slump Test:}

The concrete slump test is used for the measurement of a property of fresh concrete. The test is an empirical test that measures the workability of fresh concrete. More specifically, it measures consistency between batches. The test is popular due to the simplicity of apparatus used and simple procedure.

\subsubsection{Application of Slump test:}

1) The slump test is used to ensure uniformity for different batches of similar concrete under field conditions and to ascertain the effects of plasticizers on their introduction.
2) This test is very useful on site as a check on the day-to-day or hour- to-hour variation in the materials being fed into the mixer. An increase in slump may mean, for instance, that the moisture content of aggregate has unexpectedly increases.

3) Other cause would be a change in the grading of the aggregate, such as a deficiency of sand.

4) Too high or too low a slump gives immediate warning and enables the mixer operator to remedy the situation.

5) This application of slump test as well as its simplicity, is responsible for its widespread use.

Table 2: Workability table

\begin{tabular}{|c|c|c|c|}
\hline \multirow{2}{*}{$\begin{array}{c}\text { Degree of } \\
\text { workability }\end{array}$} & \multicolumn{2}{|c|}{ Slump } & Compacting \\
\cline { 2 - 3 } & $\mathrm{mm}$ & inches & Factor \\
\hline Very low & $0-25$ & $0-1$ & 0.78 \\
\hline Low & $25-50$ & $1-2$ & 0.85 \\
\hline Medium & $\begin{array}{c}50- \\
100\end{array}$ & $2-4$ & 0.92 \\
& & \\
\hline High & $\begin{array}{c}100- \\
175\end{array}$ & $4-7$ & 0.95 \\
& & \\
\hline
\end{tabular}

\subsubsection{Observation:}

For the conduction of slump cone test the ratio of cement and sand was kept as mentioned earlier maintain the water content ratio to 1 (water: cement: sand $=1: 2: 3$ ). For each mixture the tests were conducted separately. The results of the test were summarized in the table given below.

Table 3: Results of Slump test

\begin{tabular}{|c|c|c|c|c|}
\hline $\begin{array}{l}\text { S. } \\
\text { N } \\
\text { o. }\end{array}$ & $\begin{array}{l}\text { Concret } \\
\text { e } \\
\text { Mixture }\end{array}$ & $\begin{array}{l}\text { Slump } \\
\text { height } \\
(\mathrm{mm})\end{array}$ & $\begin{array}{c}\text { Workabilit } \\
\mathrm{y}\end{array}$ & $\begin{array}{c}\text { Compactio } \\
\text { n factor }\end{array}$ \\
\hline 1 & F0 & 7 & High & 0.95 \\
\hline 2 & F10 & 6 & High & 0.95 \\
\hline 3 & F20 & 6 & High & 0.95 \\
\hline 4 & F30 & 5 & Medium & 0.92 \\
\hline 5 & F40 & 5 & Medium & 0.92 \\
\hline 6 & F50 & 2 & Low & 0.85 \\
\hline
\end{tabular}

\subsection{Tensile Strength:}

Tensile strength is the ability of a material to withstand a pulling (tensile) force. It is customarily measured in units of force per cross-sectional area. This is an important 
concept in engineering, especially in the fields of material science, mechanical engineering and structural engineering.

The ability to resist breaking under tensile stress is one of the most important and widely measured properties of materials used in structural applications.

\subsubsection{Preparation of the sample:}

The concreted mixes consisting of various proportions of fly ash and cement are poured into the cylindrical mold of $58 \mathrm{~mm}$ inner diameter and also maintaining the $1 / \mathrm{d}$ ratio of 0.5 to 1 . After the curing period of 21 days the Brazilian test is conducted in the laboratory.

The tensile strength can be determined by the following formula,

Tensile strength $\sigma_{\mathrm{t}}=0.636 \mathrm{~F} / \mathrm{A} \mathrm{N} / \mathrm{mm}^{2}$

Where,

$\mathrm{F}=$ Load at failure

$A=$ Surface area $(d * t)$
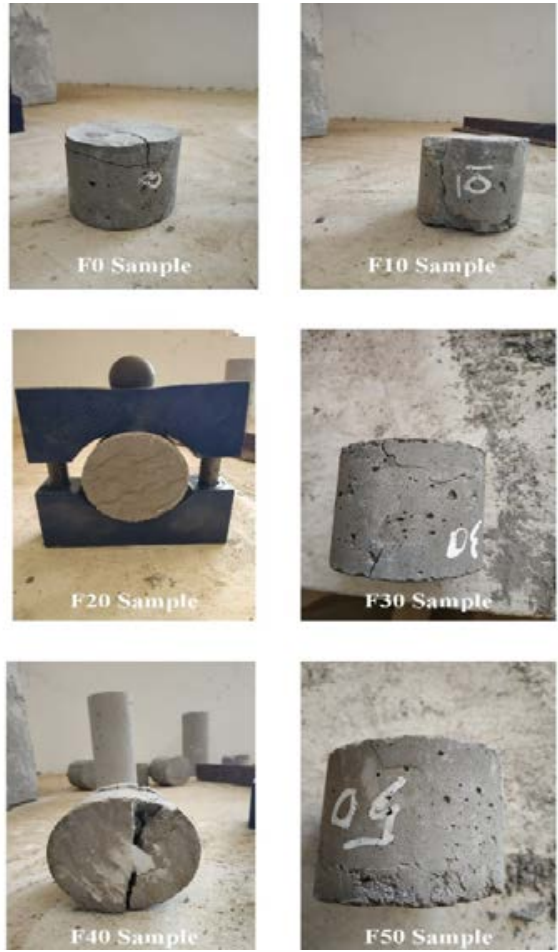

Figure 1: Failed samples in Brazilian test.

Table 4: Results of Brazilian Test

\begin{tabular}{|c|c|c|c|c|c|c|}
\hline $\begin{array}{c}\text { Si. } \\
\text { No. }\end{array}$ & Sample & $\begin{array}{c}\text { Diameter } \\
(\mathrm{d}) \\
(\mathrm{mm})\end{array}$ & $\begin{array}{c}\text { Thickness } \\
(\mathrm{t}) \\
(\mathrm{mm})\end{array}$ & $\begin{array}{c}\text { Area }(\mathrm{A}) \\
\left(\mathrm{d}^{*} \mathrm{t}\right) \\
\left(\mathrm{mm}^{2}\right)\end{array}$ & $\begin{array}{c}\text { Load at } \\
\text { failure }(\mathrm{F}) \\
(\mathrm{KN})\end{array}$ & $\begin{array}{c}\text { Tensile } \\
\text { Strength } \\
\left(\mathrm{KN} / \mathrm{mm}^{2}\right)\end{array}$ \\
\hline 1 & F0 & 58 & 46 & 2668 & 25250 & 6.02 \\
\hline 2 & F10 & 58 & 46 & 2668 & 16900 & 4.03 \\
\hline 3 & F20 & 58 & 45 & 2610 & 16750 & 4.08 \\
\hline 4 & F30 & 58 & 45 & 2610 & 23350 & 5.69 \\
\hline 5 & F40 & 58 & 47 & 2726 & 22050 & 5.14 \\
\hline 6 & F50 & 58 & 46 & 2668 & 21050 & 5.02 \\
\hline
\end{tabular}

\subsection{Uniaxial Compression Test:}

The uniaxial compressive strength (UCS) is the maximum axial compressive stress that a right-cylindrical sample of material can withstand before failing. It is also known as the unconfined compressive strength of a material because confining stress is set to zero.

\subsubsection{Preparation of the sample:}

The concreted mixes consisting of various proportions of fly ash and cement are poured into the cylindrical molds of $58 \mathrm{~mm}$ inner diameter and maintaining the $1 / d$ ratio above 2.5. After the curing period of 21 days the uniaxial compression test is conducted in the laboratory.

The UCS can be determined by the following formula,

Compressive strength $\sigma_{\mathrm{c}}=\mathrm{F} / \mathrm{A} \mathrm{N} / \mathrm{mm}^{2}$

Where, $\quad \mathrm{F}=$ Load at failure

$$
\mathrm{A}=\mathrm{c} / \mathrm{s} \text { area }=\pi \mathrm{d}^{2} / 4
$$
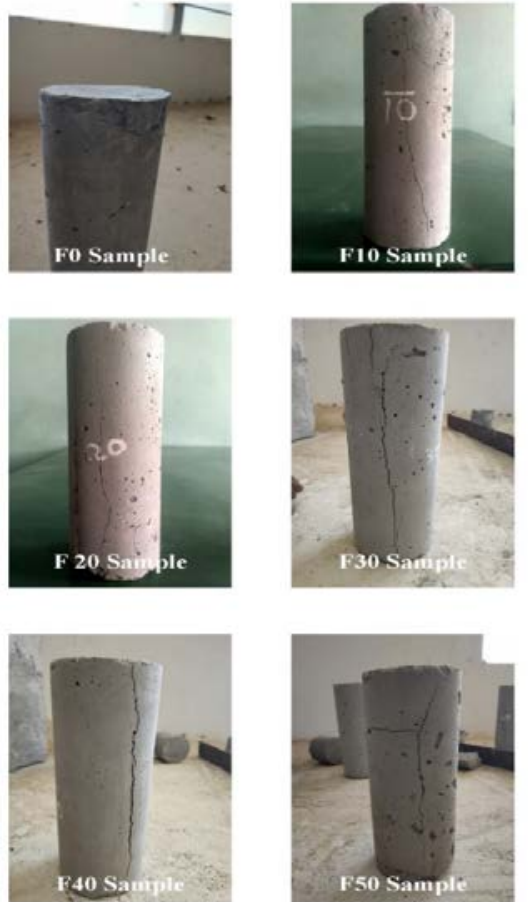

Figure 2: Failed samples in UCS Test.

Table 5: Results of UCS Test.

\begin{tabular}{|c|c|c|c|c|c|}
\hline $\begin{array}{c}\text { Si. } \\
\text { No. }\end{array}$ & Sample & $\begin{array}{c}\text { Diameter } \\
(\mathrm{d}) \\
(\mathrm{mm})\end{array}$ & $\begin{array}{c}\mathrm{c} / \mathrm{s} \text { Area A } \\
\pi d^{2} / 4 \\
\left(\mathrm{~mm}^{2}\right)\end{array}$ & $\begin{array}{c}\text { Load at } \\
\text { failure }(\mathrm{F}) \\
(\mathrm{KN})\end{array}$ & $\begin{array}{c}\mathrm{UCS} \\
\left(\mathrm{KN} / \mathrm{mm}^{2}\right)\end{array}$ \\
\hline 1 & F0 & 58 & 2642.08 & 20350 & 7.70 \\
\hline 2 & F10 & 58 & 2642.08 & 36950 & 13.99 \\
\hline 3 & F20 & 58 & 2642.08 & 38150 & 14.44 \\
\hline 4 & F30 & 58 & 2642.08 & 36250 & 13.72 \\
\hline 5 & F40 & 58 & 2642.08 & 37850 & 14.33 \\
\hline 6 & F50 & 58 & 2642.08 & 34950 & 13.23 \\
\hline
\end{tabular}




\subsection{Shear Strength:}

Shear strength is a material's ability to resist forces that can cause the internal structure of the material to slide against itself. Adhesives tend to have high shear strength.

In engineering, shear strength is the strength of a material or component against the type of yield or structural failure where the material or component fails in shear. The shear strength is the load that an object is able to withstand in a direction parallel to the face of the material, as opposed to perpendicular to the surface.

\subsubsection{Preparation of the sample:}

The concreted mixes consisting of various proportions of fly ash and cement are poured into the cylindrical mold of $54 \mathrm{~mm}$ inner diameter and also maintaining the $\mathrm{l} / \mathrm{d}$ ratio of 0.5 to 1 . After the curing period of 21 days the Shear Strength Test is conducted in the laboratory.

The shear strength can be determined by the following formula,

$$
\sigma=\frac{\mathrm{P} \sin \alpha}{\mathrm{D} * \mathrm{~L}} \quad \mathrm{Z}=\frac{\mathrm{P} \cos \alpha}{\mathrm{D} * \mathrm{~L}}
$$

Where, $\quad \sigma=$ Horizontal shear strength

$\mathrm{Z}=$ Vertical shear strength

$\mathrm{P}=$ Load at failure

$\alpha=$ Angle of inclination

$\mathrm{D}=$ Diameter of the specimen in $\mathrm{mm}$

$\mathrm{L}=$ Length of the specimen in $\mathrm{mm}$
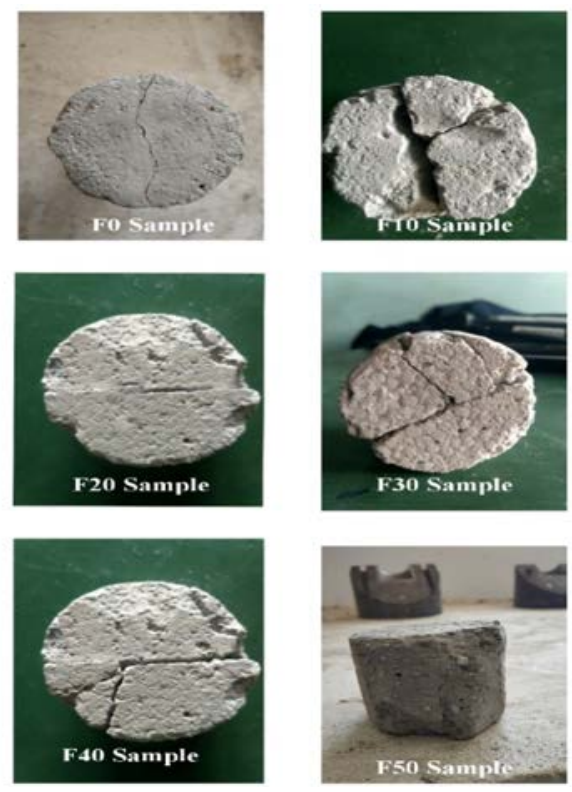

Figure 3: Failed samples in Shear Strength Test.
Table 6: Results of Shear Strength Test

\begin{tabular}{|c|c|c|c|c|c|c|c|}
\hline $\begin{array}{c}\text { Si. } \\
\text { No. }\end{array}$ & Sample & $\begin{array}{c}\text { Diameter } \\
(\mathrm{d}) \\
(\mathrm{mm})\end{array}$ & $\begin{array}{c}\text { Length } \\
(\mathrm{l}) \\
(\mathrm{mm})\end{array}$ & $\begin{array}{c}\text { Area }(\mathrm{A}) \\
\left(\mathrm{d}^{*}\right) \\
\left(\mathrm{mm}^{2}\right)\end{array}$ & $\begin{array}{c}\text { Angle of } \\
\text { inclination } \\
(\alpha)\end{array}$ & $\begin{array}{c}\text { Load at } \\
\text { failure } \\
(\mathrm{F}) \\
(\mathrm{KN})\end{array}$ & $\begin{array}{c}\text { Shear } \\
\text { strength } \\
\left(\mathrm{KN} / \mathrm{mm}^{2}\right)\end{array}$ \\
\hline 1 & F0 & 54 & 45 & 2430 & $45^{\circ}$ & 45650 & 13.28 \\
\hline 2 & F10 & 54 & 46 & 2484 & $45^{\circ}$ & 47450 & 13.51 \\
\hline 3 & F20 & 54 & 46 & 2484 & $45^{\circ}$ & 54650 & 15.56 \\
\hline 4 & F30 & 54 & 45 & 2430 & $45^{\circ}$ & 48950 & 14.24 \\
\hline 5 & F40 & 54 & 46 & 2484 & $45^{\circ}$ & 49150 & 13.99 \\
\hline 6 & F50 & 54 & 45 & 2430 & $45^{\circ}$ & 24850 & 7.23 \\
\hline
\end{tabular}

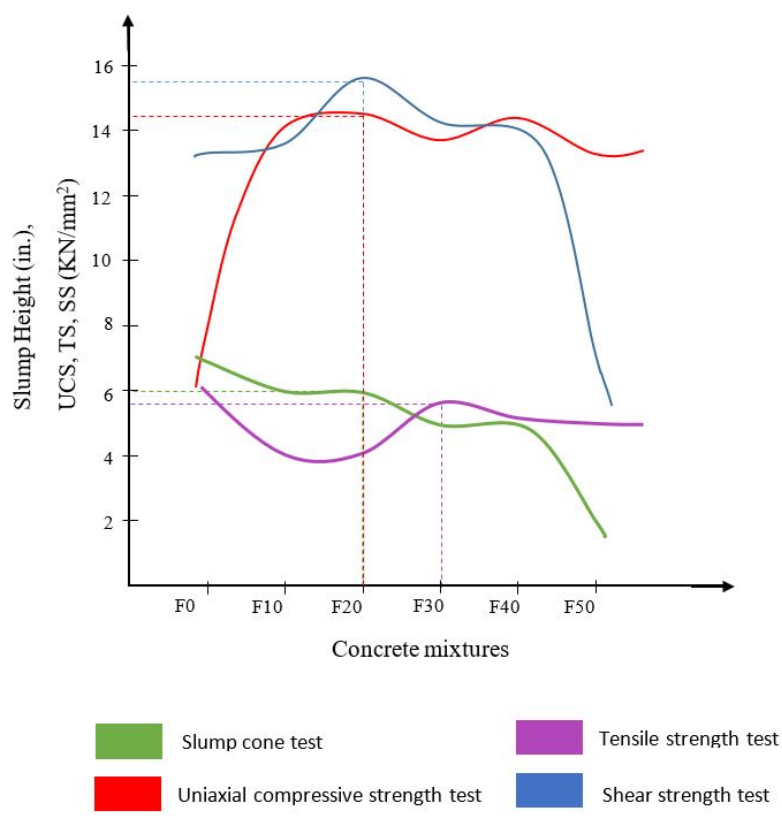

Figure 4: Graph showing results of all tests.

\section{CONCLUSION}

1) The slump cone test indicates that the F0, F10 and F20, F30 and F40 mixtures are of high workability and F50 mixture is low workable. This indicates that when the percentage of fly ash increases the compaction factor decreases and requires more amount of water to retain the workability

2) The results of uniaxial compression test indicate that the uniaxial compression strength increases when the fly ash is made as partial replacement for cement. The F20 mixture shows maximum UCS.

3) The results of Brazilian test indicate that the tensile strength decreases when the fly ash is used as partial replacement for cement. The F30 mixture shows maximum tensile strength when compared to other mixtures.

4) The results of shear strength test indicate that the shear strength increases when the fly ash is made as partial replacement for cement. 
The F20 mixture shows the maximum shear strength. It is also noticeable that for F50 the shear strength is too less.

5) The above results indicate that F20 mixture is highly workable and the UCS shear strength are considerably high but it is too weak in tensile strength. Also, it can be inferred that the moderately workable F30 mixture shows increased UCS, shear strength. Even though the tensile strength is less when compared to F0 mixture, it is considerably high when compared to other mixtures.

Therefore the lignite fly ash at $30 \%$ when made as partial replacement for cement in the concrete mixture it gives considerably increased strength to the concrete.

\section{REFERENCES}

[1] Javed I. Bhatty, John Gajda, and F. M. Miller "Commercial Demonstration of High-Carbon Fly Ash Technology in Cement Manufacturing” International Ash Utilization Symposium, University of Kentucky, USA, 2003.

[2] Nikolaos K. Koukouzas, Charalambos Vassilatos and Loannis Glarakis "Mixture of Lignite Fly Ash in Concrete: Physical and Mineralogical Characterization - Case Study from Ptolemais, Northern Greece" World of Coal Ash (WOCA), Kentucky, USA, 2005.

[3] Carolyne Namagga, Rebecca A. Atadero "Optimazation of fly ash in concrete: High Lime Fly Ash as a Replacement for Cement and Filler Material” World of Coal Ash (WOCA), Lexington, Kentucky, USA, 2009.

[4] RamaMohan Rao P \& H Sudarasan Rao Strength properties of class "C" fly ash concrete with variable aggregate binder ratio NICMAR-Journal of Construction Management, Vol. 27, No. 4, OctoberDecember, 2012

[5] T.G.S Kiran, M.K.M.V Ratnam "Fly Ash as a Partial Replacement of Cement in Concrete and Durability Study of Fly Ash in Acidic $\left(\mathrm{H}_{2} \mathrm{SO}_{4}\right)$ Environment" International Journal of Engineering Research and Development, Volume 10, Issue 12 December-2014.

[6] P. Rocha, S. Jalali, et al., "HPC using fly ash” Portugal, 2014.

[7] Mahesh. V. Raut and Shirish V. Deo "A review on effect of fly ash and fibers on shrinkage cracking and durability of concrete” 2015.

[8] JingjingFeng, Shuhua Liu, Zhigang Wang "Effects of ultrafine fly ash on the properties of high-strength concrete" Hungary, 2015.

[9] V. Sai Kiran, V. Sandeep Chowdary and P. Veerabhadra Rao "Comparison of mechanical properties of nano concrete with conventional high strength concrete” The Indian Concrete Journal, October, 2016.

[10]http://www.iricen.gov.in/LAB/res/html/ Test-24.html 